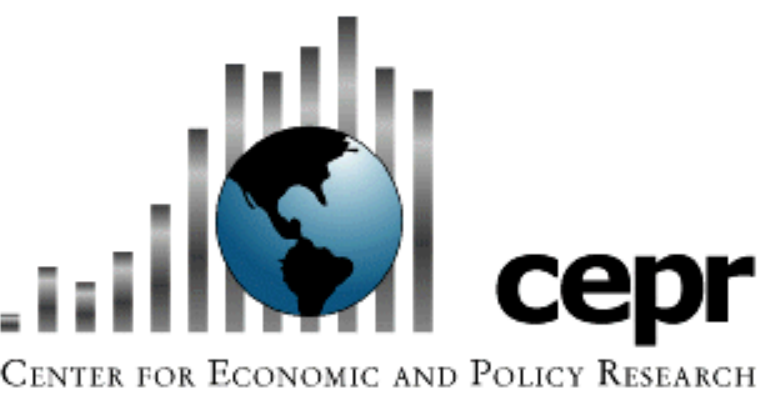

\title{
The Scorecard on Development: 25 Years of Diminished Progress
}

Authors:

Mark Weisbrot, Dean Baker, and David Rosnick

September 2005

Center for Economic and Policy Research

1611 Connecticut Avenue, NW

Suite 400

Washington, D.C. 20009

Tel: 202-293-5380

Fax: 202-588-1356

www.cepr.net 


\title{
Contents
}

\author{
Title Page i \\ Table of Contents ii \\ Executive Summary 1 \\ Introduction 3 \\ Standards of Comparison 5 \\ The Slowdown in Economic Growth 7 \\ Reduced Progress in Heath Outcomes 9 \\ Reduced Progress in Education 15 \\ Exceptions: China and India 21 \\ Conclusion: What Went Wrong? 24
}

\section{About the Authors}

Mark Weisbrot and Dean Baker are Co-Directors and David Rosnick is a Senior Research Associate at the Center for Economic and Policy Research

\section{Acknowledgments}

Egor Kraev, Luis Sandoval, Dan Beeton, Ji Hee Kim, Jamie Strawbridge, and Nihar Bhatt provided research assistance for this paper. 


\section{Executive Summary}

This paper looks at the available data on economic growth and various social indicators - including health outcomes and education - and compares the last 25 years (1980-2005) ${ }^{1}$ with the prior two decades (1960-1980). The paper finds that, contrary to popular belief, the past 25 years (1980-2005) have seen a sharply slower rate of economic growth and reduced progress on social indicators for the vast majority of low- and middle-income countries.

Countries are divided into quintiles on the basis of their starting point at the beginning of each period. The study therefore does not compare the performance of the same country over the two periods, because this would tend to find reduced progress for the second period due to "diminishing returns." In other words, it would be more difficult for a country to move from a life expectancy of 70 to 75 , than from 50 to 55. By comparing the performance of countries that start out at a certain level in 1960, with countries that start out at the same level in 1980, this study avoids the possibility of interpreting such inherent limits on progress as evidence of failure in the second period.

\section{Among the findings:}

- A sharp fall-off in the growth of GDP per capita was found for all groups of countries except the bottom quintile. (See Figure 1) In the fourth quintile, marked by per capita incomes between \$1238 and \$2364, growth falls from 2.4 percent annually in the first period to 0.7 percent in the second period. To get an idea how much difference this makes over time, at 2.4 percent growth the country's income per person will double in about 29 years. At 0.7 percent growth, it would take 99 years.
The middle quintile, with GDP per capita between \$2364 and \$4031, drops from a 2.6 percent growth rate in the first period to 1 percent in the second. The second quintile (\$4086-8977) falls even further: from 3.1 percent in the first period to 1.3 percent in the second period.

Even the top quintile, which at $\$ 9012$ to $\$ 43,713$ contains a mixture of middle-income and highincome countries shows a sizeable falloff in growth, from 2.6 percent in the first period to only 1.3 percent in the second period.

The only group which does not show a slowdown in growth is the bottom quintile, with per capita income between $\$ 355$ and $\$ 1225$ annually, where growth increases slightly, from 1.7 to 1.8 percent. However this is still not a good average performance for the poorest developing countries, and the slight improvement disappears without India and China.

- A decline in the rate of improvement for life expectancy was found for the vast majority of low- and middle-income countries. (See Figure 2) The biggest drop was in the fourth quintile, with life expectancy between 44 and 53. These countries saw an average annual increase of 0.56 years for 1960-1980, but almost no progress -0.03 years for the second period. Over 20 or 25 years this makes a large difference. For the first period, countries in this quintile increased their life expectancy by about 11 years. If this rate of improvement had continued, the countries in this quintile in the second period would have raised life expectancy by 12 years; instead they saw an increase of only 0.7 years.

The bottom, middle, and second quintiles also saw declines in the rate of progress. The only

\footnotetext{
${ }^{1}$ Or most recent available year.
} 
exception was the highest quintile, with life expectancy between 69 and 76 years. This quintile showed some improvement in the second period, which was driven by the highincome countries in the group.

- A decline in the rate of improvement for adult mortality was found for male and female adults, for most groups. (See Figures $\mathbf{5}$ and 6). For females, all quintiles except the best one show worse performance for the second period, with the fourth quintile showing an actual increase (rather than a decline in the rate of reduction) in mortality rates. For males, the bottom three quintiles show worse performance for the second period, with the fourth quintile showing an actual increase in mortality rates.

- A decline in the rate of progress for child (under 5) mortality was found across all quintiles, although the reduction in progress is relatively small in the top two quintiles. (See Figure 7).

- A decline in the rate of improvement for infant mortality was found for all groups of countries. (See Figure 8).

- A reduction in the rate of increase of public spending on education was found for all groups of countries. (See Figure 9). For the higher income countries, this is partly attributable to demographic changes.

- A reduction in the rate of increase in secondary school enrollment was also found across all groups of countries, in addition to a reduced rate of increase for primary school enrollment for the bottom two quintiles.

\section{Implications}

Over the past 25 years a number of economic reforms have taken place in low and middle-income countries.
These reforms, as a group, have been given various labels: "liberalization," "globalization," or "free-market" 2 are among the most common descriptions. Among the reforms widely implemented have been the reduction of restrictions on international trade and capital flows, large-scale privatizations of state-owned enterprises, tighter fiscal and monetary policies (higher interest rates), labor market reforms, and increasing accumulation of foreign reserve holdings. There is a general consensus that the majority of developing countries have benefited economically from the reforms, even if they have sometimes been accompanied by increasing inequality or other unintended consequences.

The evidence in this paper indicates that this consensus could be mistaken. The trends in growth rates and social indicators are overwhelmingly in the same direction, showing a reduced rate of progress over the last 25 years. It is generally difficult to show a clear relationship between any particular policy change and economic outcomes, especially across countries. There are many changes that take place at the same time, and causality is difficult to establish. It is certainly possible that the decline in economic and social progress that has taken place over the last 25 years would have been even worse in the absence of the policy changes that were adopted. But that remains to be demonstrated. In the meantime, a long-term failure of the type documented here should at the very least shift the burden of proof to those who maintain that the major policy changes of the last 25 years have raised living standards in the majority of developing countries, and encourage skepticism with regard to economists or institutions who believe they have found a formula for economic growth and development. Most importantly, the outcome of the last 25 years should have economists and policy-makers thinking about what has gone wrong.

\footnotetext{
${ }^{2}$ The latter term, as well as "free trade," is inaccurate as a matter of economics, since the reforms have included very costly forms of protectionism - e.g. increased patent and copyright protection - as well as such policies as fixed exchange rates, which are the opposite of "free-market" policies.
} 


\section{Introduction}

Over the past 25 years a number of economic reforms have taken place in low and middle-income countries. These reforms, as a group, have been given various labels: "liberalization," "globalization," or "free-market" 3 are among the most common descriptions. Among the reforms widely implemented have been the reduction of restrictions on international trade and capital flows, large-scale privatizations of state-owned enterprises, tighter fiscal and monetary policies (higher interest rates), labor market reforms, and increasing accumulation of foreign reserve holdings. Many of these reforms have been implemented with the active support of multilateral lending institutions such as the International Monetary Fund and the World Bank, as well as the G-7 governments, and have often been required in order for countries to have access to credit from these and other sources. But regardless of origin, labels or political perspectives, there is a general consensus that the majority of developing countries have benefited economically from the reforms, even if they have sometimes been accompanied by increasing inequality or other unintended consequences. ${ }^{4}$

\footnotetext{
${ }^{3}$ The latter term, as well as "free trade," is inaccurate as a matter of economics, since the reforms have included very costly forms of protectionism - e.g. increased patent and copyright protection - as well as such policies as fixed exchange rates, which are the opposite of "free-market" policies.

4 "Globalisation has brought enormous benefits in growth and efficiency. Yet this same force has brought cross-border financial crises and heightened the imperative to bring into the mainstream those who are being left behind." - Rodrigo De Rato, Managing Director of the IMF, Financial Times (September 14, 2005).
}

This paper looks at the available data on economic growth and various social indicators - including health outcomes and education - and finds that, contrary to popular belief, the past 25 years have seen a sharply slower rate of economic growth and reduced progress on social indicators for the vast majority of low and middle-income countries. Of course it is still possible that some or even all of the policy reforms of the past 25 years have had net positive effects, or that they will have such an impact at some point in the future. But the fact that these effects have not yet shown up in the data, for developing countries as a group - and that in fact the data show a marked decline in progress over the last quarter-century - is very significant. If the data and trends presented below were well known, it would very likely have an impact on policy discussions and research. Most importantly, there would be a much greater interest in finding out what has gone wrong over the last 25 years.

In order to evaluate the progress of the last 25 years, it is necessary to have a benchmark for comparison. In other words, for the world as a whole, there is almost always economic growth, technological progress, and therefore social progress over time. The relevant question is not whether there has been income growth and social progress, but the rate of such progress as compared with what has been feasible in the past.

For this paper, we have chosen to compare the past 25 years $(1980-2005)^{5}$ with the previous 20 years: 1960-1980. This is a fair comparison. While the 1960s were a period

\footnotetext{
${ }^{5}$ For some indicators the most recent data does not extend to 2005, e.g. life expectancy goes only to 2002.
}

...contrary to popular belief, the past 25 years

have seen a sharply slower rate of economic growth and reduced progress on social indicators for the vast majority of low and middleincome countries.

The relevant question is not whether there has been income growth and social progress, but the rate of such progress as compared with what has been feasible in the past. 
of exceptional economic performance, the 1970s suffered from two major oil shocks that led to worldwide recessions: in 1974-75, and again at the end of the decade. The seventies were also a period of high inflation in both developing and developed countries. So this twenty-year period is not a particularly high benchmark for comparison with the most recent 25 years. If the 1950s were included, it would have made the benchmark for comparison higher, since the 1950s were generally a period of good growth for the developing world. But there is not much good data for the 1950s; and many of the developing countries did not become independent until the late 1950s or 1960s. 


\section{Standards of Comparison}

O ne way to compare the performance of the two periods (1980-2005 and 1960-1980) would be to simply compare how each group of countries did in the first period, with the same group of countries' performance for the second period. The problem with such a comparison is that it may be more difficult to make the same amount of progress from a higher level than when starting from a lower level. For example, this is certainly true for some levels of life expectancy: it would be more difficult to raise life expectancy from 70 to 75 years than to raise it from 50 to 55. A comparison of the same countries for the two periods would therefore tend to find a diminished rate of progress simply because of this inherent difficulty that comes from progress during the first period. This is not what we want to measure.
To get around this problem, we divide the countries into five groups, depending on their starting point at the beginning of each of the two periods. For example, if we look at Figure 1, there are five groups of countries sorted by per capita income. The middle quintile includes countries with an income per person between $\$ 2364$ and $\$ 4031$ (in constant 2000 dollars). These are countries that started out either in 1960 or 1980 with a GD P per person in this range. The other quintiles range from the poorest (\$355-1225) to the richest $(\$ 9012-\$ 43,713)$.

Looking at the middle quintile, at the bottom of the graph we can see that there were 24 countries that started the 1960s in this range of per capita GDP (\$2364 to \$4031), but 33 countries that started the 1980s in this

Figure 1: Average Annual Growth by Income Quintile and Period

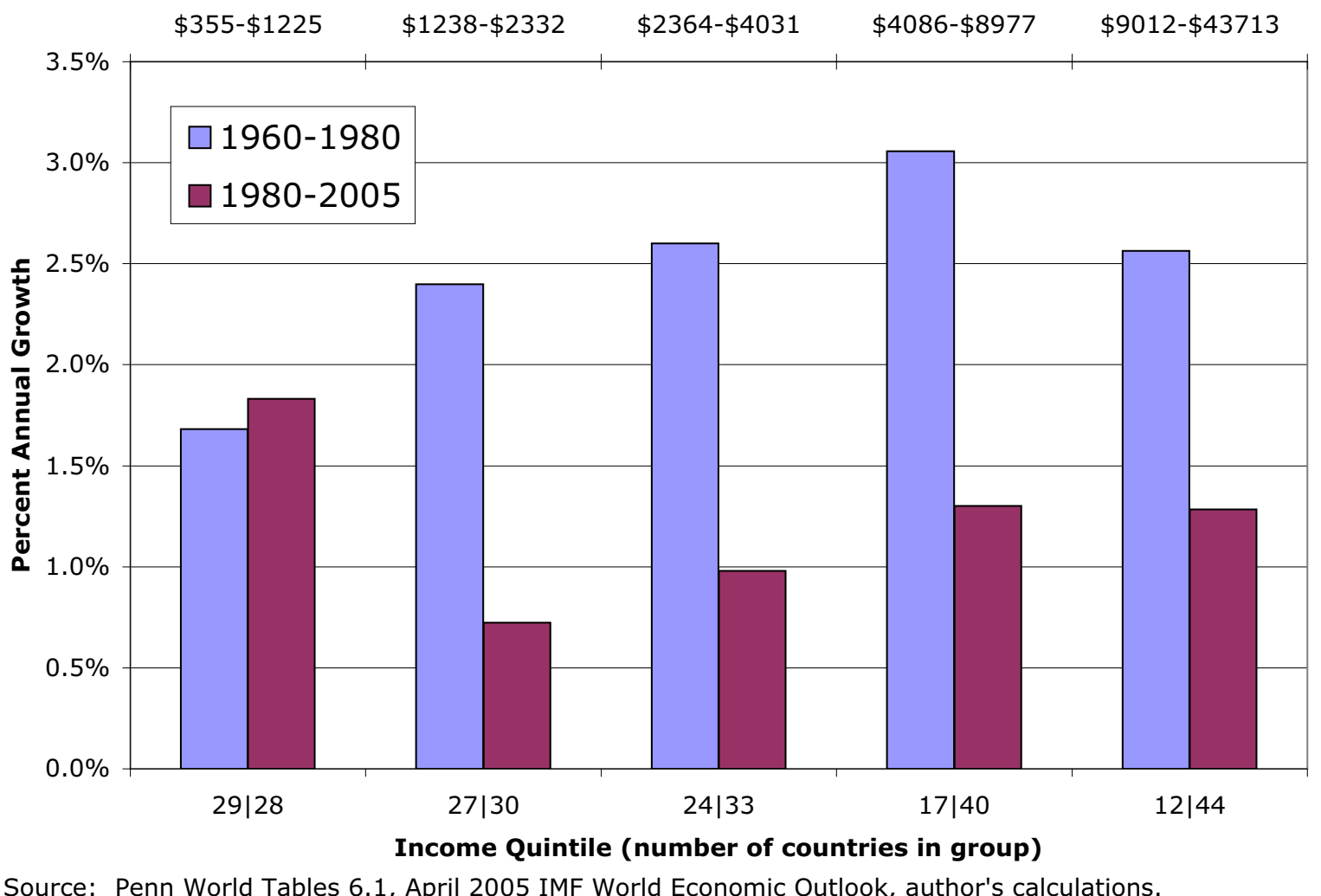

Source: Penn World Tables 6.1, April 2005 IMF World Economic Outlook, author's calculations. 
range. This is to be expected, as some of the countries from the bottom two quintiles moved into the middle quintile as a result of their growth during the first period. ${ }^{6}$

On this basis, we can make a fair comparison - not of the same countries over time, which would suffer from the problems described above - but between all the countries that started the first period at a certain level of income, and all the countries that started the second period at that same level. We can do the same for the social indicators as well.

In fact, this methodology should bias the data towards finding better results for the second period. There should generally be possibilities for countries to gain by borrowing from the technology and practices of other countries that are richer or have achieved higher levels of the various social indicators. As a result of the progress made in the first period, there were far more possibilities for faster improvement in the second period. For example, in the case of life expectancy(Figure 2), there were only 16 countries at the start of the first period (1960) with life expectancy of more than 69 years. This meant that countries in the next lowest grouping, with life expectancies from 63 to 69 years, would have a relatively limited number of countries from which to adopt better public health measures, medicines, or medical practices. However, at the start of the second period (1980), there were 50 countries with life expectancies of more than 69 years. This should have provided a far larger set of practices that the countries in the second grouping (with life expectancies from 63 to 69 years) could adopt to improve health care in their own country in the second period. The same would also be true for all the countries further down the ladder in life expectancy.

\footnotetext{
${ }^{6}$ In this data set there are also 65 countries (out of 175) for which there are only data for the 1980-2005 period, and not for 1960-1980. The number of countries in each group also changes as countries move up from one quintile to the next on the basis of progress in the first period.
}

In other words, it is reasonable to expect that countries starting at any particular level (e.g. of income or life expectancy) will perform better in the second period (1980 to 2005), simply because the advance of technology and knowledge over 20 years has created more and better practices that are available to be adopted. 


\section{The Slowdown in Economic Growth}

The growth of income (or G DP) per person is the most basic measure of economic progress that economists use. Of course this ignores the distribution of income, as well as environmental and health outcomes. And there are things that raise GDP that do not increase human welfare: e.g. more people buying cigarettes and alcohol and then having to be treated for resulting health impairment. But as a broad measure of economic progress it is by far the most important. When we look at GDP per person, we are deliberately factoring out population growth, since any growth in the economy that is only due to population growth does not improve living standards. Ignoring for the moment any change in labor force participation, we are really looking at productivity growth. For developing countries especially, it is the increase in productivity over time that enables a country to have higher living standards. As productivity grows, a smaller proportion of the country's resources is allocated to the necessities of life, and more can be dedicated to education, health care, and investment in future growth. In general, and especially over long enough periods of time, productivity growth will improve the lives of the majority of the population, including the poor. ${ }^{7}$ To the extent that any of the reduced progress over the last 25 years measured by social indicators, as noted in subsequent sections of this paper is due to economic changes - and much of it is - it is almost certainly due to declining growth rates rather than changes in the distribution of income. ${ }^{8}$

Figure 1 shows the annual rate of growth of GDP (or income) per capita for the two periods (1960-1980 and 1980-2005). The 175 countries are divided into quintiles

\footnotetext{
${ }^{7}$ See e.g. D ollar, D avid and A art Kraay. 2000. "G rowth is G ood for the Poor." The World Bank. A remarkable exception to such longterm trends has been the United States over the last 30 years, where the median wage has increased only about 9 percent, while productivity increased by more than 80 percent.

${ }^{8}$ This is not to say that redistribution - whether from existing income or wealth, or new income created through growth - is unimportant or undesirable. Indeed, as the UND P points out, it can potentially make a large difference in poverty reduction (see UND P, Human D evelopment Report, pp. 64-71).
}

according to their per capita income at the start of each period, as explained above. There is a pronounced slowdown in growth for each quintile, except for the bottom quintile. Taking the three middle quintiles first, which are all low- and middle-income countries, the difference between the two periods is striking. In the fourth quintile, marked by incomes between $\$ 1238$ and \$2332, growth falls from 2.4 percent annually in the first period to 0.7 percent in the second period. To get an idea how much difference this makes over time, at 2.4 percent growth the country's income per person will double in about 29 years. At 0.7 percent growth, it would take 99 years.

The declines in the next two quintiles are also severe. The middle quintile, with G D P per capita between $\$ 2364$ and $\$ 4031$, drops from a 2.6 percent growth rate in the first period to 1 percent in the second. The second quintile (\$4086-8977) falls even further: from 3.1 percent in the first period to 1.3 percent in the second period.

Even the top quintile, which at $\$ 9012$ to $\$ 43,713$ contains a mixture of middle-income and high-income countries shows a sizeable falloff in growth, from 2.6 percent in the first period to only 1.3 percent in the second period. It is worth noting that in the top quintile, the result is mainly driven by the middle-income countries.

As noted above, the comparison in each of these quintiles is not for the same countries over the two periods, but for the countries that start each period at the level of income defined by the per capita income boundaries of the quintile. Some countries will move up to higher levels, as we would expect on the basis of progress between 1960-1980. So, for example, Sri Lanka, Indonesia, Lesotho, and the Gambia all started out in the bottom quintile in 1960 but began the second period (1980) in the next quintile up. Morocco, Thailand, and Botswana moved two quintiles, from the bottom to the third (middle) quintile. At the bottom of the table is listed 
the number of countries in each quintile, for 1960 and 1980.

The only group which does not show a slowdown in growth is the bottom quintile, with per capita income between $\$ 355$ and $\$ 1225$ annually, where growth increases slightly, from 1.7 to 1.8 percent. However this is still a bad average performance for the poorest developing countries. It is worth noting that this result is reversed without India and China, despite the fact that that India and China are counted in the averages here with no more weight than small countries such as Mali or Burundi. That is, the averages are not weighted by either GDP or population. (Since China and India together account for approximately half of the population of the developing world, their experiences are discussed separately in the last section.) So it is only the large jump in their growth rates in the second period that drives the improvement for the bottom quintile. It is also worth noting that the improvement for the bottom quintile is also dependent on the countries that were not in the data set for 1960-1980, but are included for 1980-2005.

In any case there is no ambiguity about the overall result, which does not depend on how the countries are divided into groups or whether the new countries are included. There is a sharp slowdown in the rate of growth of per capita income for the vast majority of low- and middleincome countries. This is probably the most important economic change that has taken place in the world during the last quarter century. It is much more difficult to reduce poverty or inequality in the face of such a growth slowdown. When a country's economy is growing, it is at least possible for the poor to share equally or even disproportionately in the gains from productivity growth. When there is very little growth in income per person, such improvements are much harder to achieve, and may be politically impossible to the extent that poverty alleviation depends on actually reducing the current income of the middle and upper classes.
One region that has been particularly affected by this growth slowdown has been Latin America. Income per capita for the region grew by more than 80 percent from 1960-1979, but only about 11 percent from 1980-2000 and 3 percent for 2000-2005. This has been a drastic change. If Brazil, for example, had continued to grow at its pre-1980 rate, the country would have European living standards today. Mexico would not be far behind. Instead, the region has suffered its worst 25-year economic performance in modern Latin American history, even including the years of the $\mathrm{G}$ reat D epression.

This is a region that adopted many of the policy reforms that have characterized the last 25 years. The average tariff on imported goods was cut by about half from 1970 to $2000 .{ }^{9}$ Controls on the inflow and outflow of investment were either removed or drastically reduced in most countries. Privatization of state-owned enterprises was undertaken on a massive scale: it amounted to 178 billion dollars in the 1990s, more than 20 times the value of privatization in Russia after the collapse of the Soviet Union..$^{10}$ Latin American countries also adopted more than 80 IMF programs during the last 25 years. These programs generally required higher real interest rates as well as budget cuts, which led to reductions in social spending - as well as other forms of liberalization.

As a result of this long-term economic failure, many Latin Americans have blamed the reforms, which are often labeled "neoliberalism" there. In the last seven years there have been a number of elections - in Venezuela, Argentina, Brazil, Ecuador, and Uruguay - where the winning candidates campaigned against "neoliberalism," and political unrest in other countries based on the same theme. Still, the long-term growth slowdown, whether in Latin America or in the developing world generally, has attracted little attention or debate in policy circles in the United States.

\footnotetext{
${ }^{9}$ World D evelopment Indicators, 2005

${ }^{10} \mathrm{G}$ lobal D evelopment Finance, 2001, World Bank. Tables A4.2 and A4.3, p. 186
} 


\section{Reduced Progress in Health Outcomes}

As would be expected in a period of sharply reduced economic growth, the last 25 years also shows slower progress on health outcomes. Figure 2 shows the result for life expectancy, with countries divided into quintiles according to their life expectancy at the beginning of each period. As can be seen in the graph, there is a noticeable slowdown in all groups except the highest quintile, which contains countries where life expectancy is between 69 and 76 years.

The biggest drop was in the fourth quintile, with life expectancy between 44 and 53. These countries saw an average annual increase of 0.56 years for 1960-1980, but almost no progress -0.03 percent for the second period. Over 20 or 25 years this makes a large difference.
For the first period, countries in this quintile increased their life expectancy by about 11 years. If this rate of improvement had continued, the countries in this quintile in the second period would have raised life expectancy by 12 years; instead they saw an increase of only 0.7 years.

The middle and bottom quintiles also show reduced progress. The bottom quintile, with life expectancies between 31 and 44 years, falls from 0.4 years to 0.24 years annual improvement. Over the 22 years of the second period, this means that life expectancy would have increased by 4 years more than it actually did, if not for this fall-off in the rate of progress. For the middle quintile, with life expectancies between 53 and 63 years,

Figure 2: Life Expectancy at Birth, total

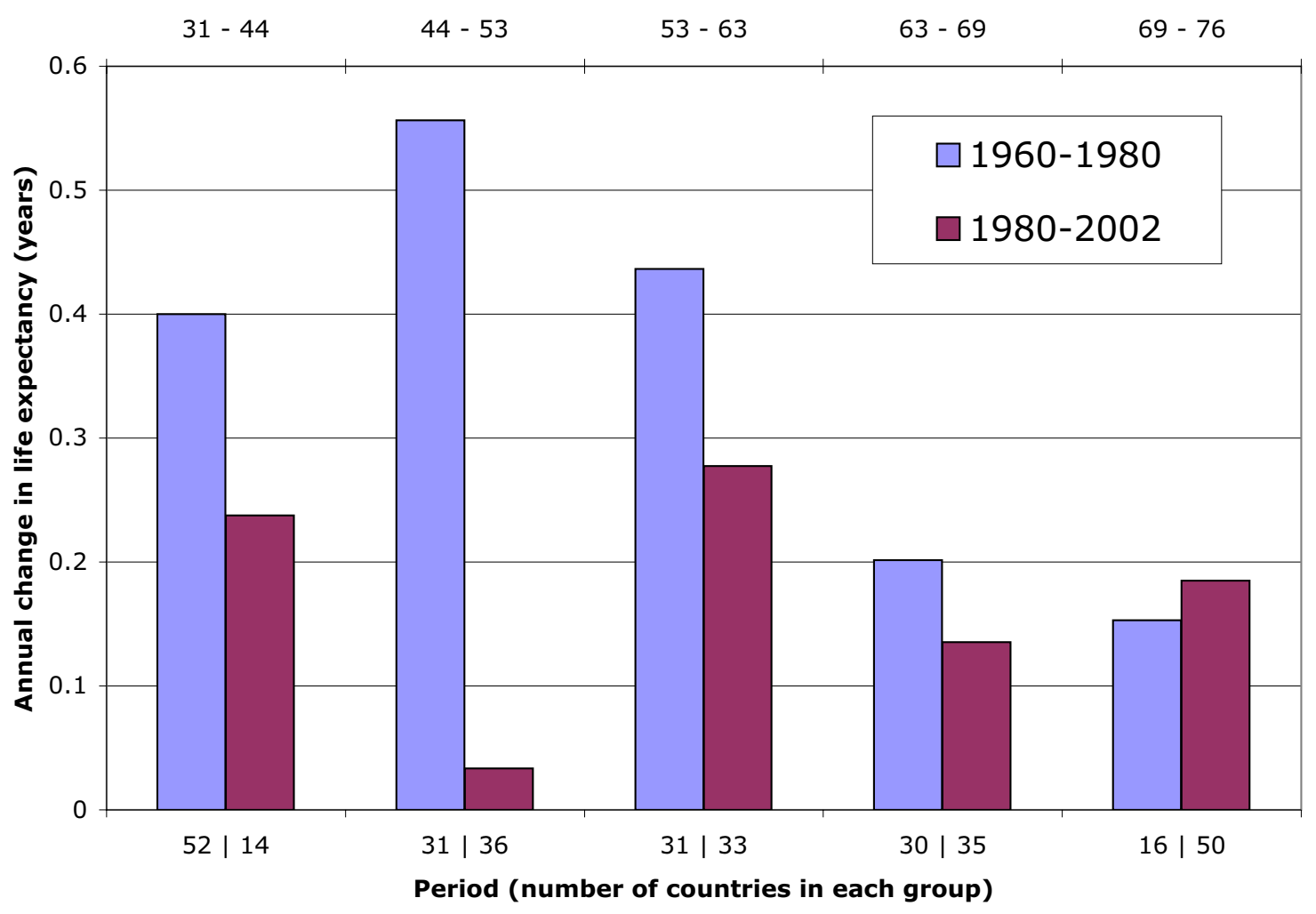


there is a decline from 0.44 to 0.28 years of annual improvement. The second quintile shows a smaller reduction, from 0.20 to 0.14 years. It is worth noting that even this difference is not insignificant, adding up to a difference of about one year of life expectancy over the 22 years.

A significant part of this story is Sub-Saharan Africa, which dominates the bottom two quintiles for the 19802005 period, and has some impact on the middle quintile. However, even if all the Sub-Saharan African countries are removed from the data, there is still a decline in progress for the bottom three quintiles, with no change for the second. So the decline in progress on life expectancy occurs across a broad range of low- and middle-income countries, and is not confined to any particular region. Furthermore, the reduced life expectancies from HIV/AIDS and even the armed conflicts in Africa are not necessarily completely exogenous. Per capita income in Sub-Saharan Africa grew by a modest, but still significant 36 percent from 19601980. From 1980-2000, income per capita actually declined - a rare event in modern economic history over a 20-year period - by about 15 percent. It is possible that some countries may have been able to deal with the HIV/AIDS and other public health crises at least somewhat more effectively if not for the economic collapse of the second period. Also, the spread of AID S is itself partly a result of the increased trade and travel, including migrant and transport labor, associated with international economic integration. For all the benefits that countries can gain as a result of increased commerce, a potential drawback is the more rapid spread of diseases. Finally, it is possible that the continent would have seen less armed conflict over the second period if not for the economic collapse that took place.

Figures 3 and 4 show the results for life expectancy for males and females separately. The boundaries for the five quintiles are different from each other and from the

Figure 3: Life Expectancy at Birth, male

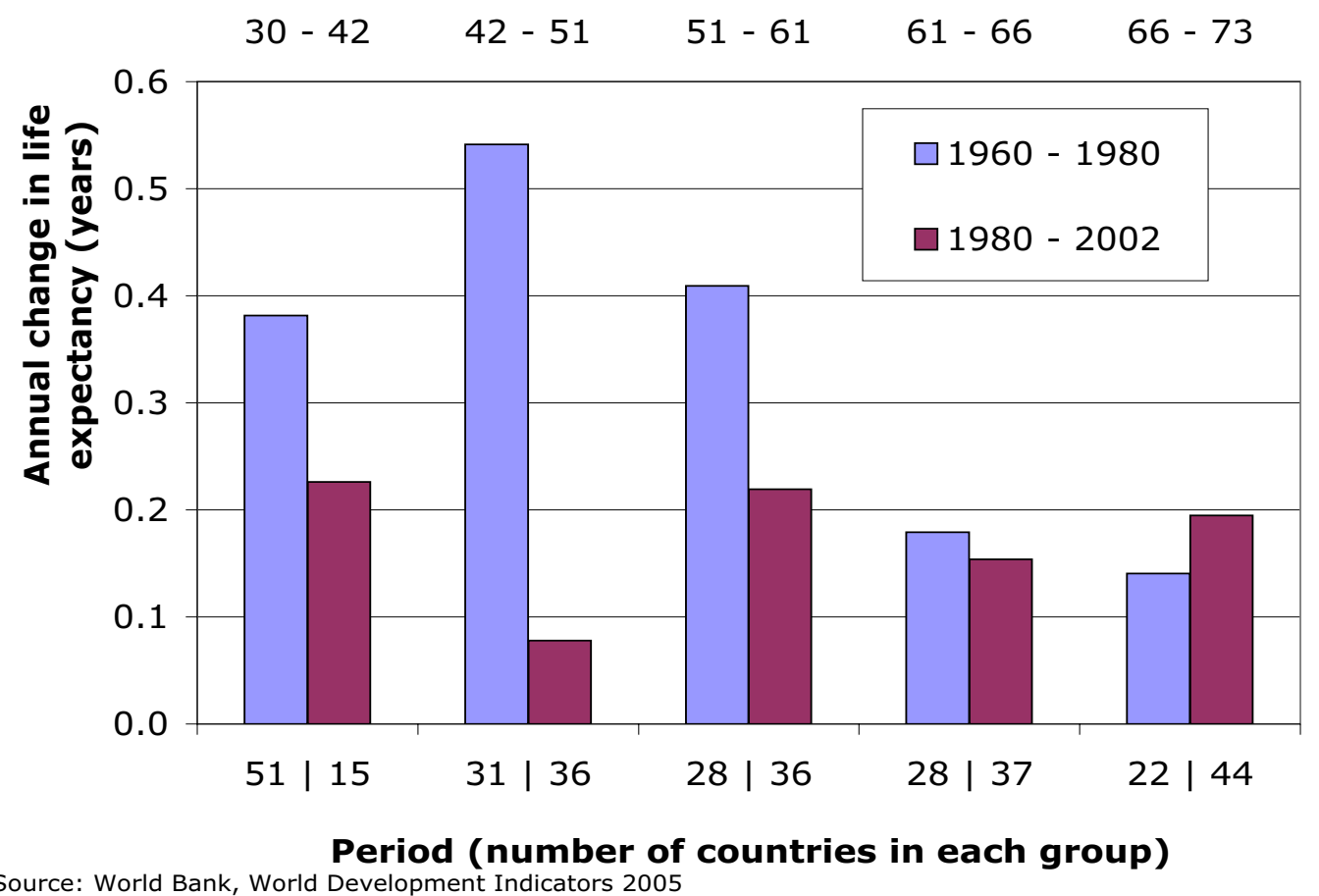




\section{Figure 4: Life Expectancy at Birth, female}

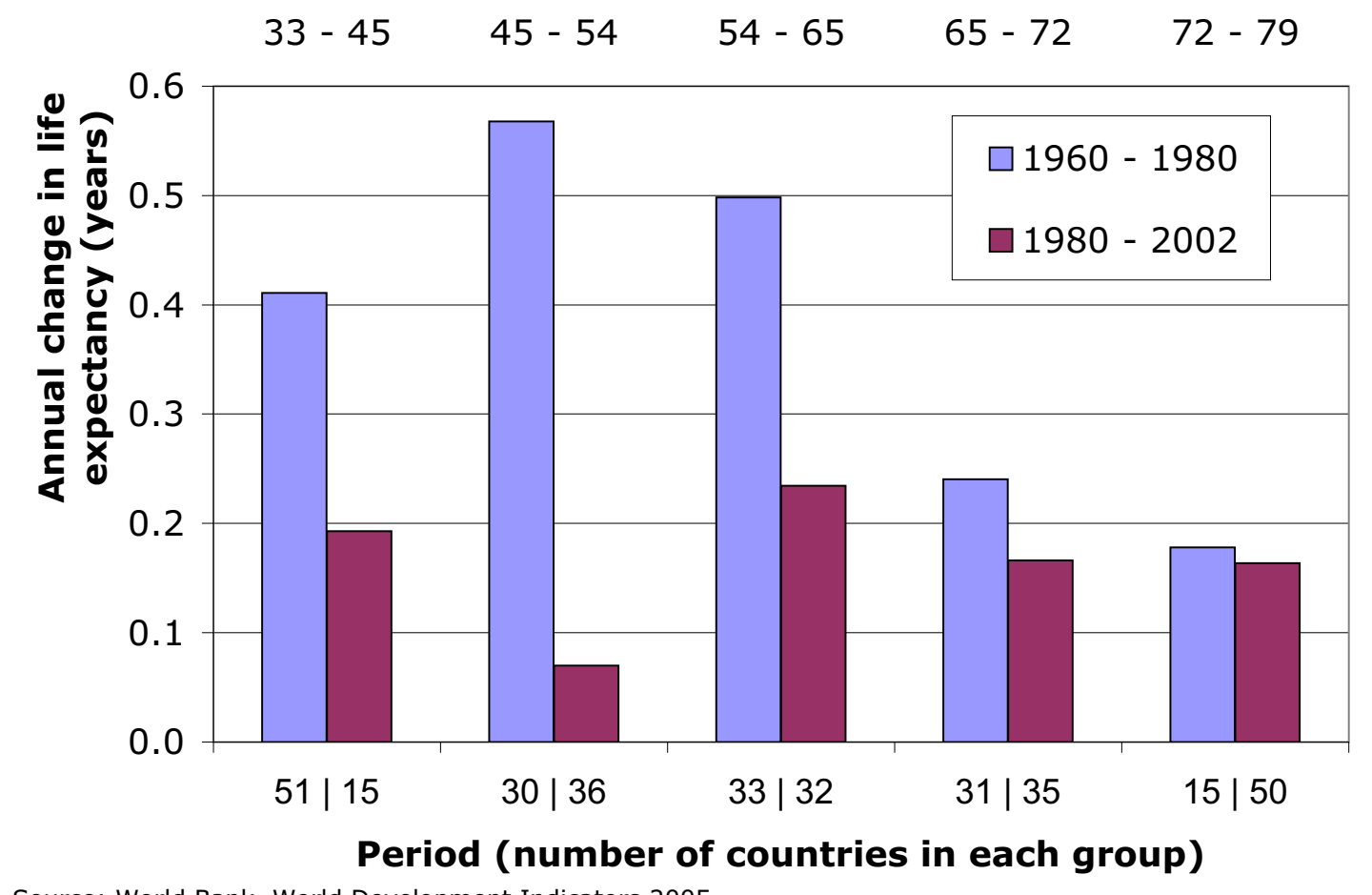

Source: World Bank, World Development Indicators 2005

overall boundaries in Figure 2, because of the higher overall life expectancy for females. But the quintiles are roughly comparable. The results are similar to the overall result in Figure 2 for the bottom four quintiles, with somewhat more of a decline in the second quintile for females. The top quintile is different, with males actually showing an improvement in the growth of life expectancy in the second period, while females do not. The increase in progress for male life expectancy in the top quintile is driven by high-income countries. ${ }^{11}$

Figures 5 and 6 show mortality rates for male and female adults, respectively. ${ }^{12}$ These are arranged in the opposite

\footnotetext{
${ }^{11}$ This includes Canada, France, Australia, Luxembourg, Belgium, Germany, New Zealand, and Kuwait.

${ }^{12}$ These mortality rates measure the probability of a 15 -year-old dying before age 60 (in deaths per 1,000)
}

direction from the previous charts, with the worst quintiles on the right. For both males and females, the bottom three quintiles show a noticeable reduction in the rate of progress during the second period. For the fourth quintile, with mortality rates between $270-415$ for women and 342-498 for men, there is an actual increase in mortality of 3.4 per thousand and 2.6 per thousand annually, respectively, in the second period. The middle quintile for males also has an increase in mortality rates, as compared to an annual average 3.8 per thousand decrease per year during the first period.

For females, the second quintile, with mortality rates of 108-165 per thousand, also shows a decline from a 1.7 per thousand annual improvement in the first period to no improvement in the second period. Male mortality for the second quintile (195-250 per thousand) shows 
Figure 5: Adult Mortality Rate, male

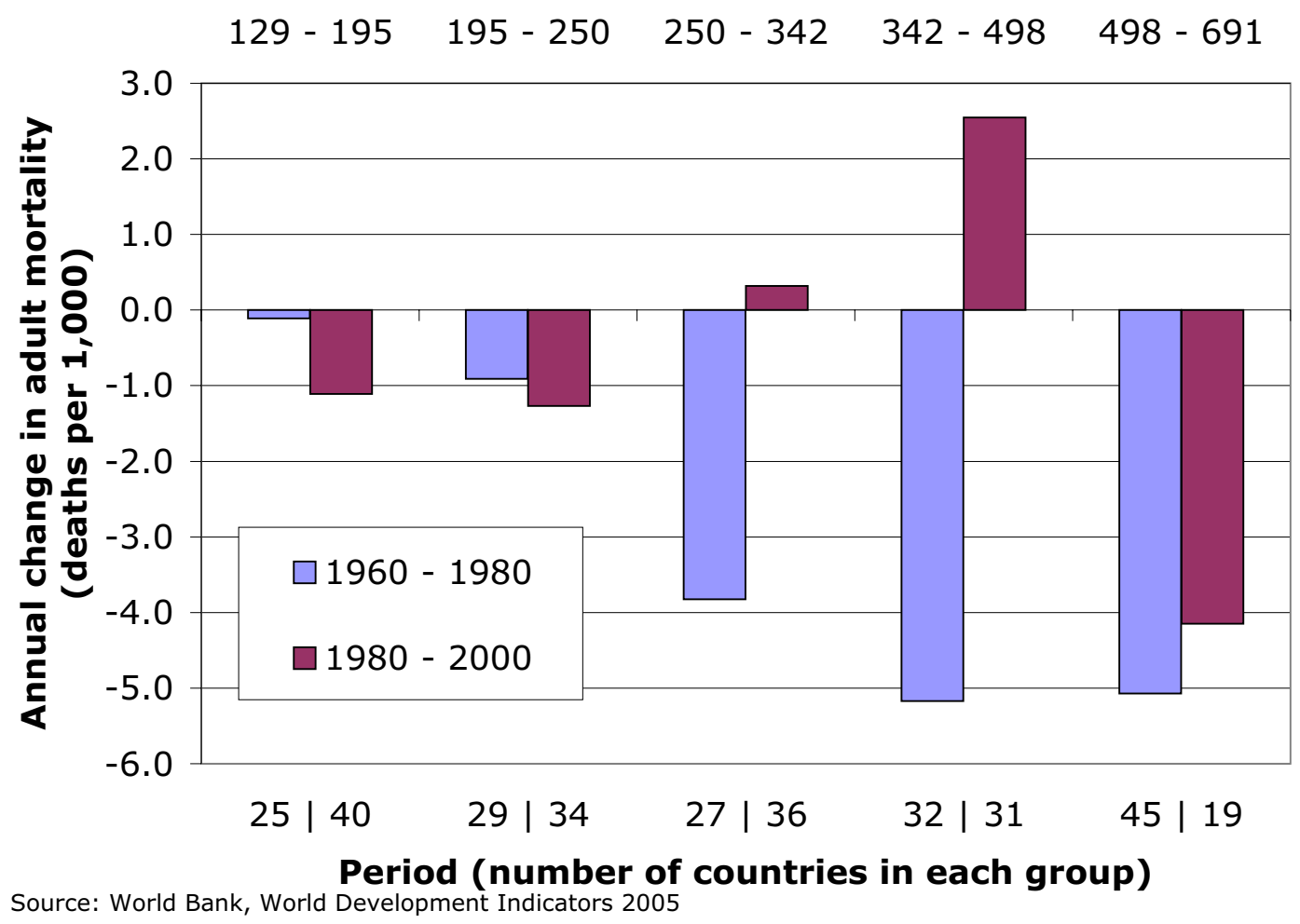

slightly better reduction for the second period. In the top quintile, both males and females show improved progress on mortality. As with the data for life expectancy, this improvement is driven by the high-income countries in this quintile.

The trends in mortality are also heavily influenced by Sub-Saharan Africa, where the HIV/ AID S crisis and armed conflict have greatly increased mortality. According to the UNDP, the conflict in the eastern part of the D emocratic Republic of the Congo has resulted in an estimated 3.8 million "excess deaths" from just 1998-2004, as compared with what would have occurred in the absence of war. But the decline in adult mortality for low- and middle-income countries is not determined by Sub-Saharan Africa. If the Sub-Saharan African countries are eliminated from the data set for Figure 4, the bottom two quintiles still show huge declines in the rate of improvement of mortality, with the middle quintile showing no change. And for the reasons described above, the region should be included.

Figure 7 shows the data for mortality rates for children under five. This data shows a declining rate of progress for all five quintiles, although the reduction in progress is relatively small in the top two quintiles. The biggest fall-off is for countries in the worst quintile, with child mortality rates of 227-390 per thousand. The rate of progress - average annual reduction - falls from 5 per thousand for 1960-1980 to 3 per thousand from 1980 to $2002 .{ }^{13}$ For this second period, the cumulative effect of this reduced progress is an increase in the child mortality rate of 44 per thousand, or more than the entire child mortality rate for the best quintile. The next two quintiles, with child mortality rates of 154-227 and 80-

\footnotetext{
${ }^{13}$ For World D evelopment Indicators February 2005, the last available year for this data is 2002 .
} 
Figure 6: Adult Mortality Rate, female

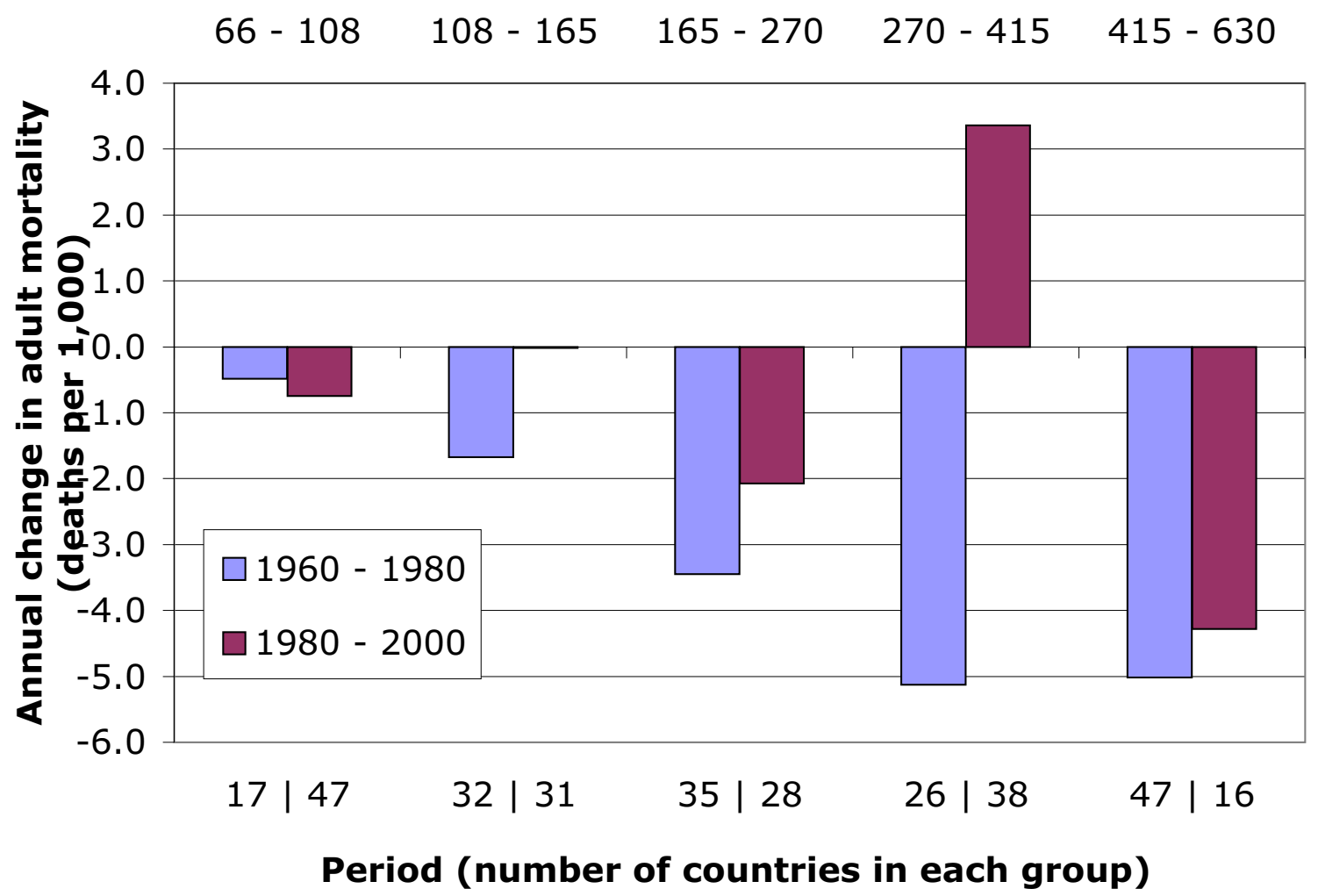

Source: World Bank, World Development Indicators 2005

154 per thousand also show much reduced progress in reducing child mortality.

Figure 8 shows the decline in infant mortality rates for the two periods, arranged by quintiles. Once again, the reduction in progress is across the board. Even the top two quintiles, which are not influenced by Sub-Saharan Africa, show declining progress for the 1980-2002 period. The sharpest fall-off in the rate of progress is for the fourth quintile, where infant mortality fell by an average of 2.6 per thousand each year from 1960-1980, but only 1.3 per thousand from 1980-2002. For the period as a whole this means that the average country in this quintile has an infant mortality rate about 29 per thousand more than it would have had if the progress of the first period had continued. For a country at the midpoint of this quintile, e.g. 122 per thousand, this represents a 31 percent higher infant mortality relative to what could have been achieved just on the basis of past progress.

Summing up the data on health outcomes, there is a significant drop in the rate of progress for the vast majority of low- and middle-income countries. This is true for life expectancy, infant and child mortality, and adult mortality in the second period (since 1980) as compared with the first period (1960-1980). There are a few groups of countries that run counter to this result, but the overall trend is very clear. 
Figure 7: Mortality Rate, under-5

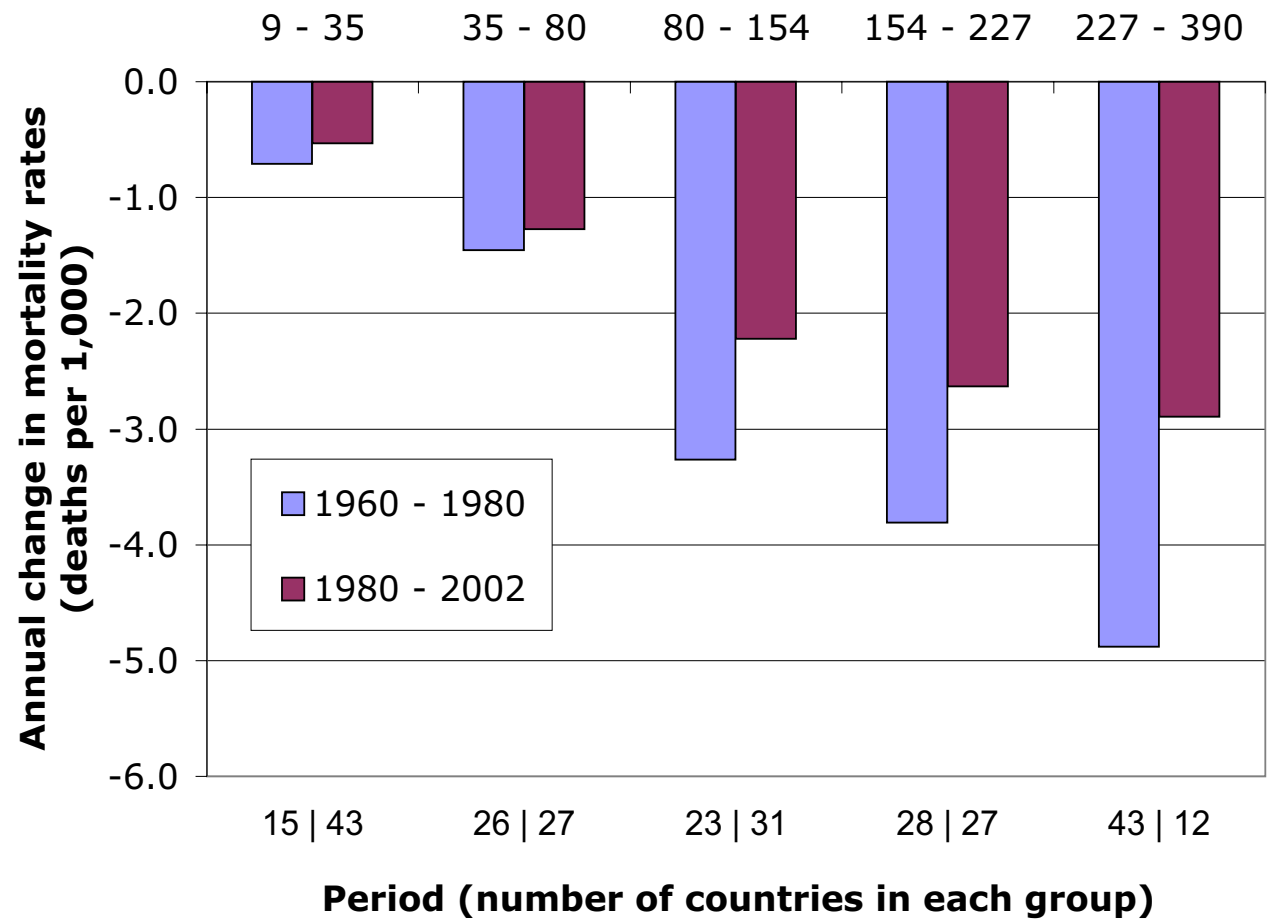

Source: World Bank, World Development Indicators 2005

Figure 8: Mortality Rate, infant

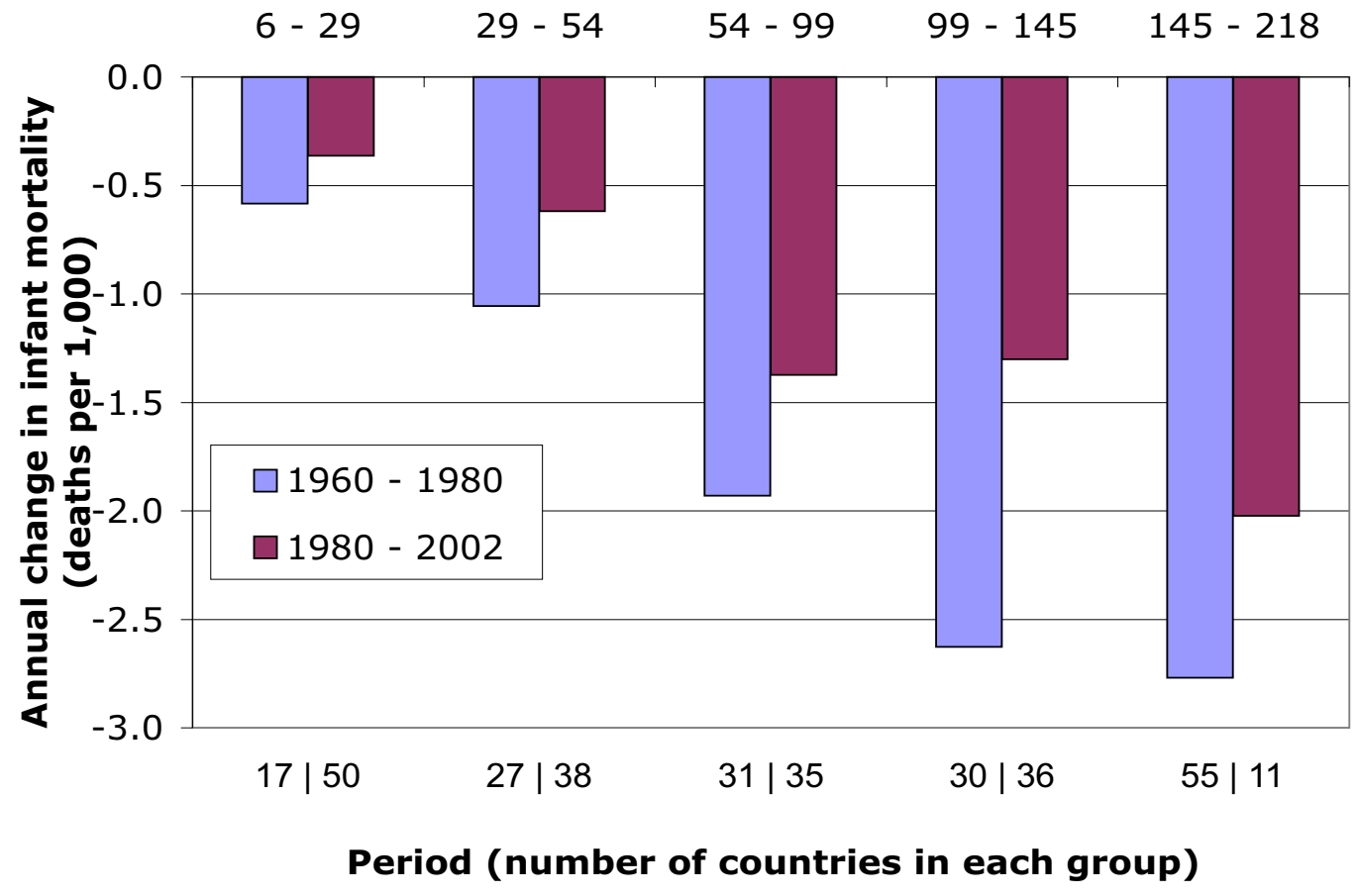




\section{Reduced Progress in Education}

Given the sharp slowdown in economic growth, it would not be surprising to find that public spending on education did not increase as much in the second period as in the first, and that is indeed the case. Figure 9 shows the average annual change in public spending on education for the two periods, as a percentage of GNP. There is a reduction in the rate of growth of education spending in all quintiles. For the middle quintile, for example, the rate of growth falls from 0.10 to 0.04 percentage points annually. This would make a difference of about 1.3 percent of GDP over a 20 year period for illustration, for the United States today this would be $\$ 150$ billion of education spending per year. The top quintile, with countries spending between 5 and 8 percent of GDP on education, shows an actual reduction of education spending during the second period. Some of this is undoubtedly due to demographics, as the higher income countries especially experienced a reduction in the number of school age children. However, this would be less of an explanation in countries that were not already spending a large percentage of their GDP on education. The slower rate of increase in public spending on education for the middle three groups is unlikely to be a result of just demographic changes.

Given the slowing growth in expenditures on public education, we would expect reduced progress in educational outcomes, unless there were large and widespread improvements in the efficiency of education. Figure 10 shows the average annual change in the percentage of students enrolled in primary school. This measures the number of students enrolled as a percentage of their age groups. It is possible for the number to exceed 100 percent, as in the top two quintiles, due to adults taking remedial or literacy classes. The bottom two quintiles show a noticeable decline in the rate of growth of primary school enrollment from the first to the second period. The middle quintile is nearly flat, and the second quintile (with enrollment between 98 and 108 percent) shows some improvement. The top quintile shows a faster rate of decline in the second period as compared with the first, but that is not necessarily harmful; for the higher income countries, it could represent a reduction in the number of adults that need remedial primary education classes. Figures 11 and 12 look at the same changes in primary school enrollment broken down by gender, for male and female primary school students and school-age children. The overall changes are similar, although the levels of enrollment for females are lower than for males, reflecting a widespread gender bias in education that prevails in many developing countries.

Figures 13,14, and 15 show changes in secondary school enrollment overall, and for males and females, respectively. There is a decline in the rate of growth of secondary school enrollment - again as a percentage of the population in this age group - across all quintiles, from the first period to the second. The only exception is the bottom quintile for females, with an average enrollment of 0-4 percent, which is flat.

Figure 16 shows the average annual changes in tertiary school enrollment, which is more mixed than the others. Only the fourth quintile, with just 1-3 percent of its population in tertiary education, shows reduced progress in the second period. The others are flat or show improvement, with the largest improvement in the second quintile (10-18 percent enrolled), which moves from a 0.7 to a 1.2 percentage point annual increase.

Figure 17 shows the average annual percentage point change in literacy. The third and second quintiles, with literacy rates of 56-76 percent and 76-92 percent, respectively, show a slower rate of progress during the second period. The other quintiles are essentially the same for the two periods.

Summing up the data on education, most low- and middle-income countries made less progress since 1980 in increasing enrollment at the primary and secondary levels of education, as compared with the prior period 
(1960-1980). This was not true for tertiary education. Public spending on education also increased at a slower rate in the second period, and the rate of progress on literacy also slowed. This - together with the slowdown in economic growth - could explain the reduced progress for low- and middle-income countries on the educational front. The changes in measures of educational progress are not as pronounced as indicators of health outcomes, or of economic growth, but they are overwhelmingly in the same direction, showing reduced progress since 1980 .

Figure 9: Public Spending on Education, total

$0-1$

$1-2$

$2-3$

$3-5$

$5-8$

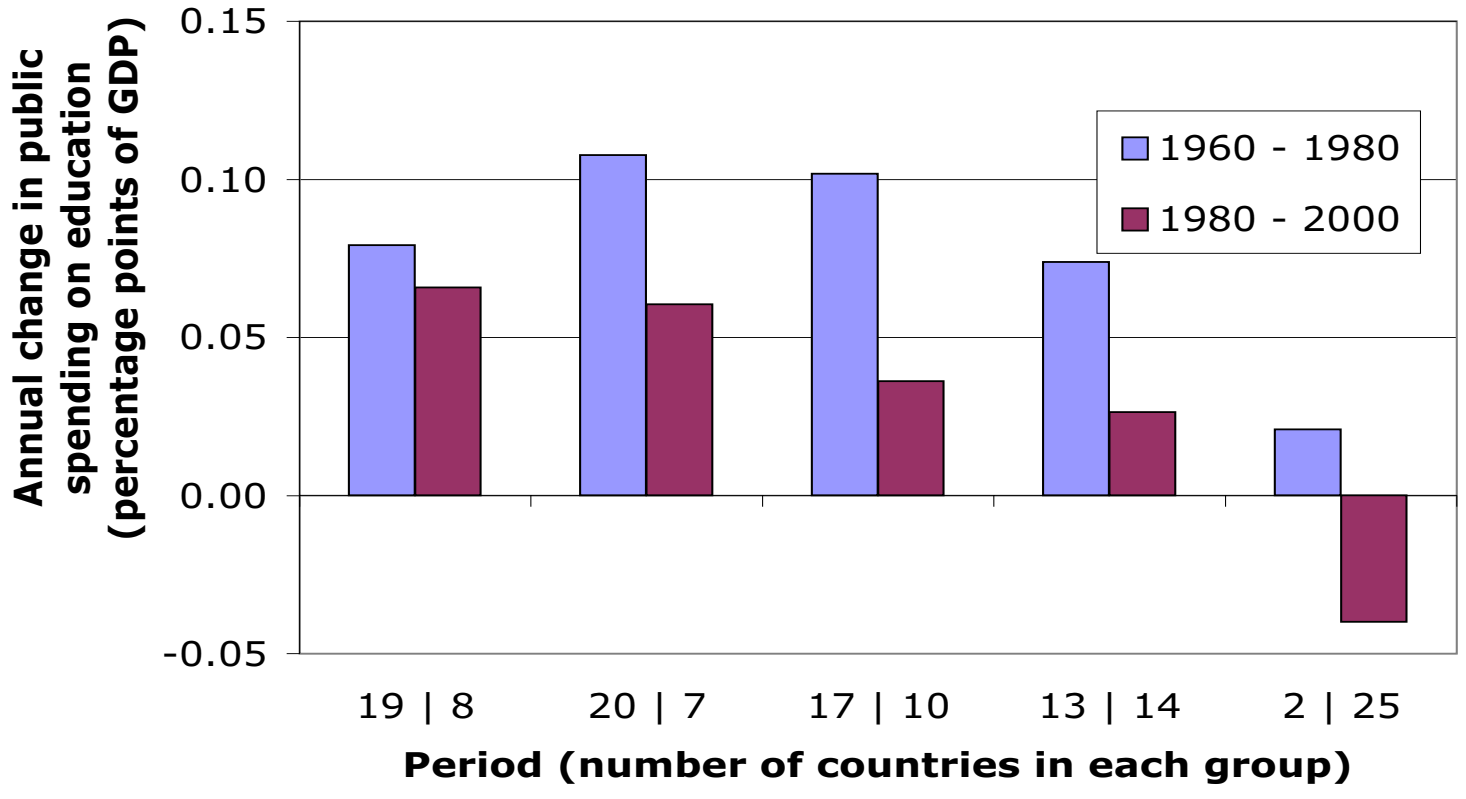

Source: World Bank, World Development Indicators 2005 
Figure 10: Primary School Enrollment, total

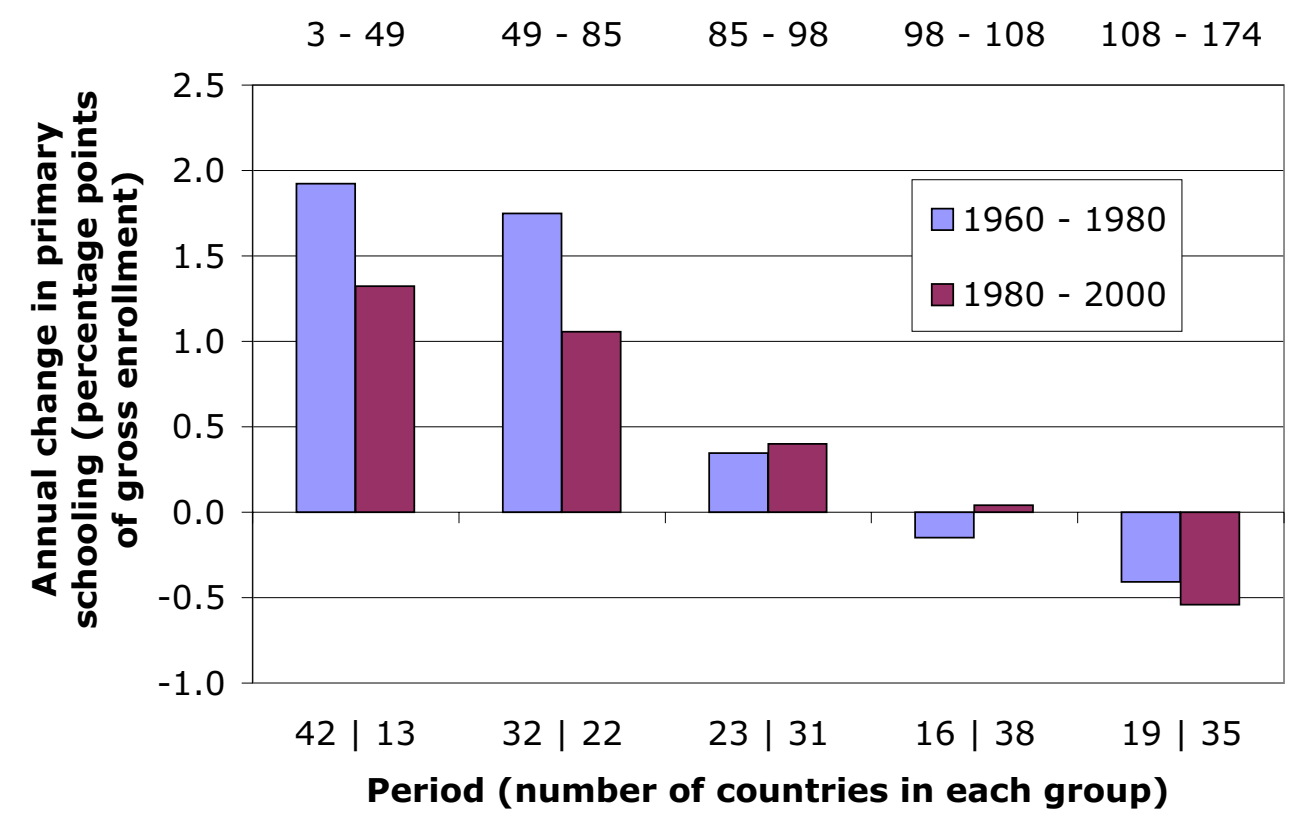

Source: World Bank, World Development Indicators 2005

Figure 11: Primary School Enrollment, male

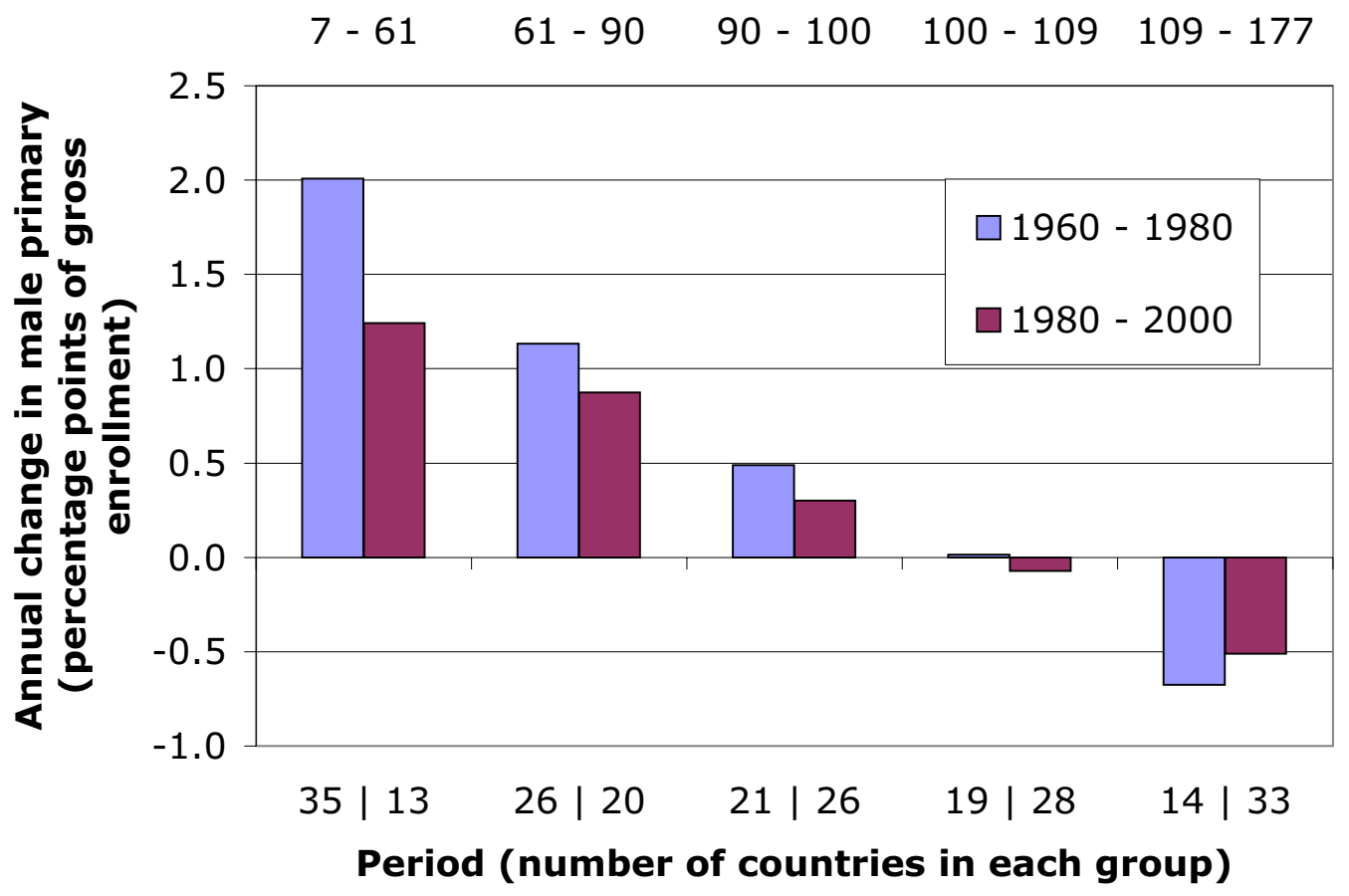


Figure 12: Primary School Erollment, female

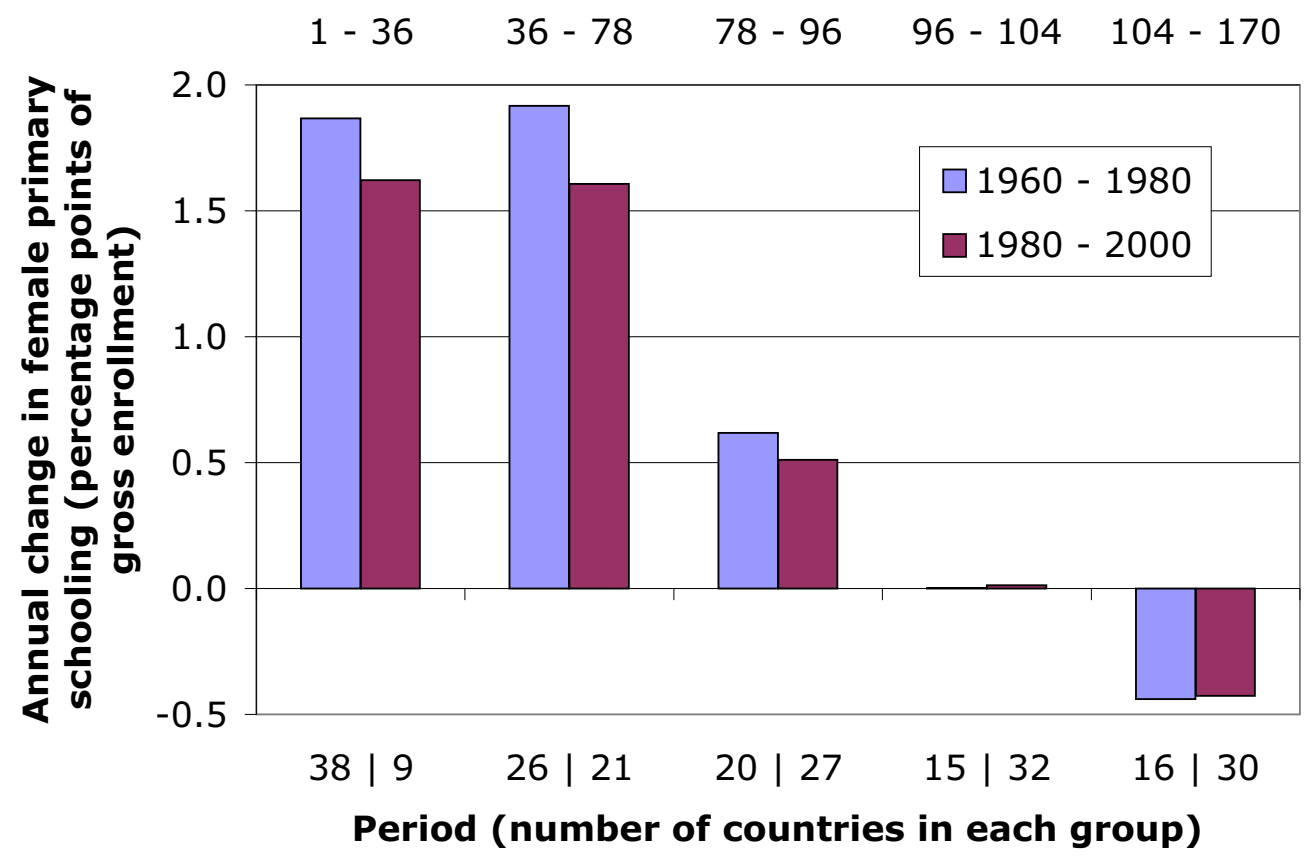

Source: World Bank, World Development Indicators 2005

Figure 13: Secondary School Enrollment, total

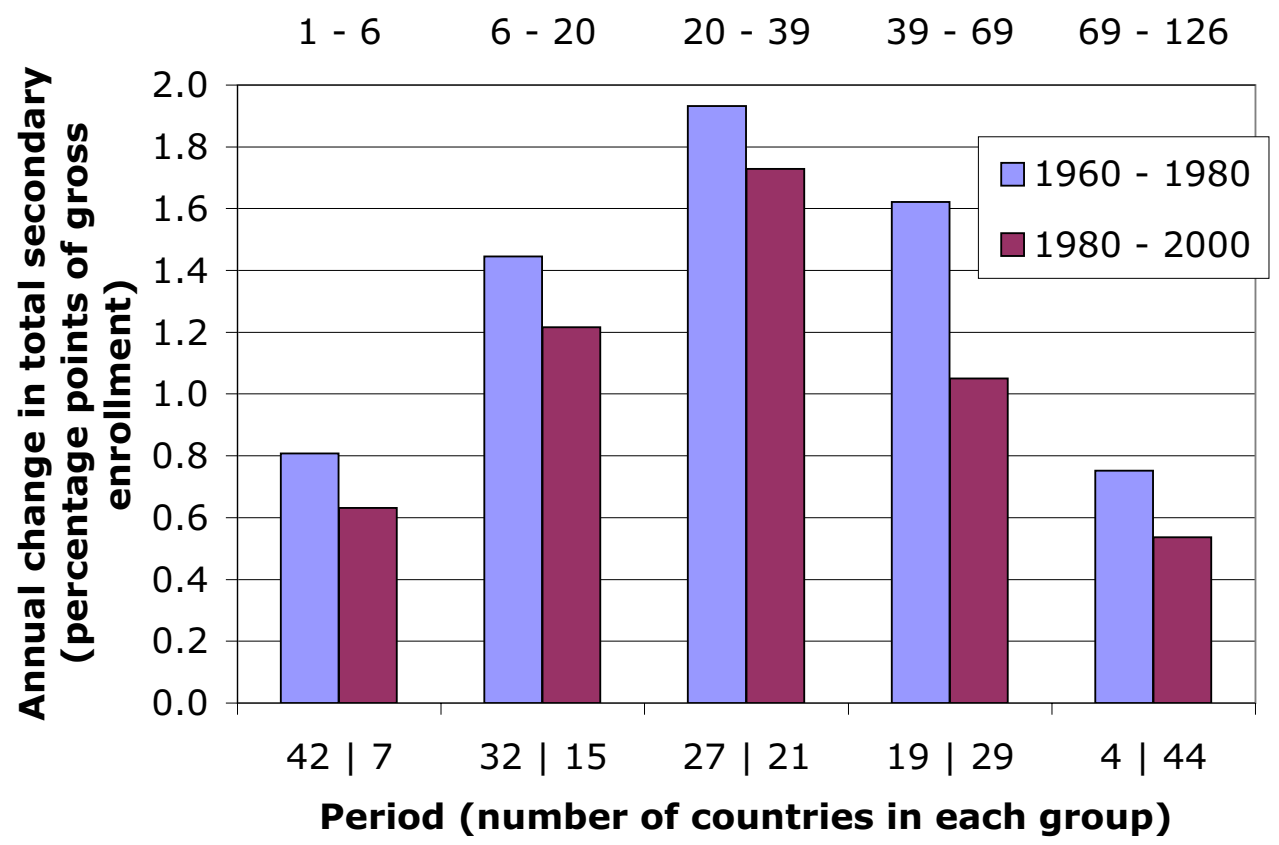


Figure 14: Secondary School Enrollment, male

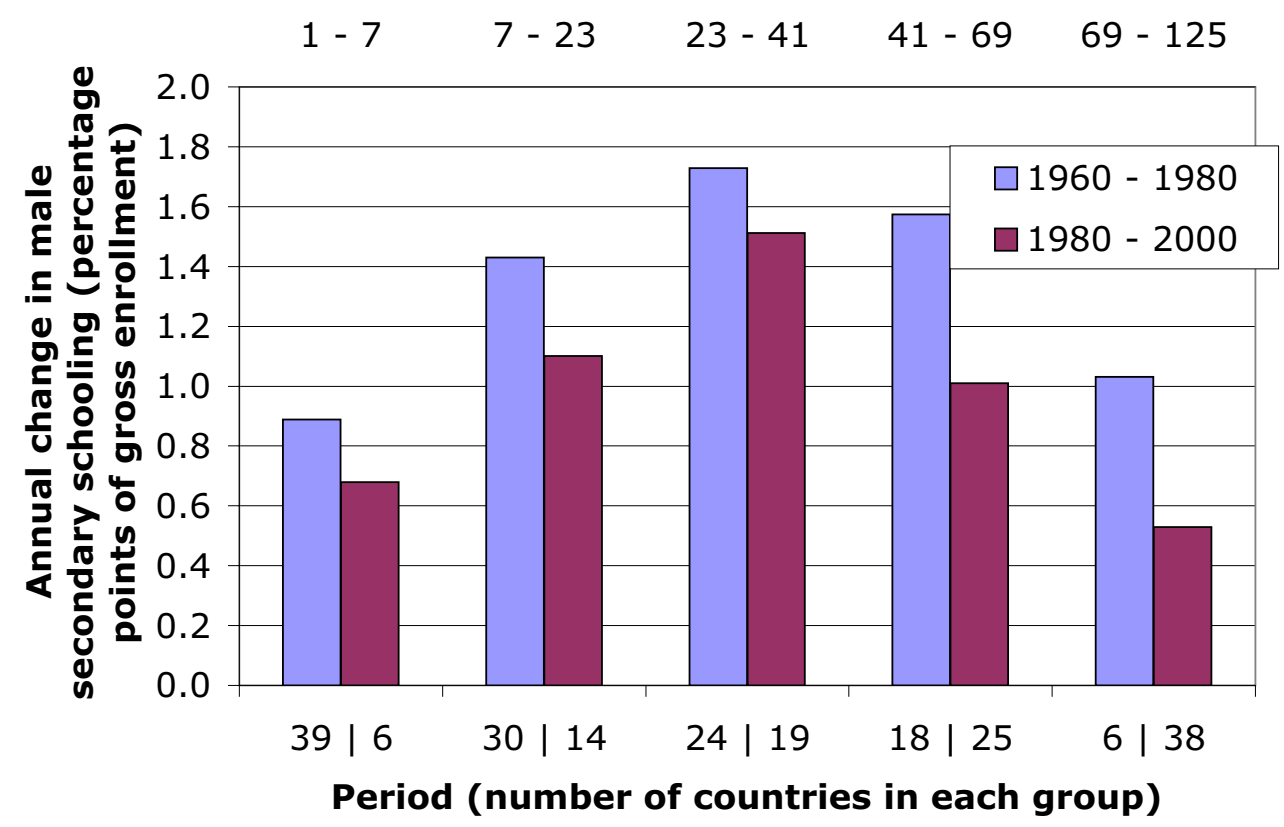

Source: World Bank, World Development Indicators 2005

Figure 15: Secondary School Enrollment, female

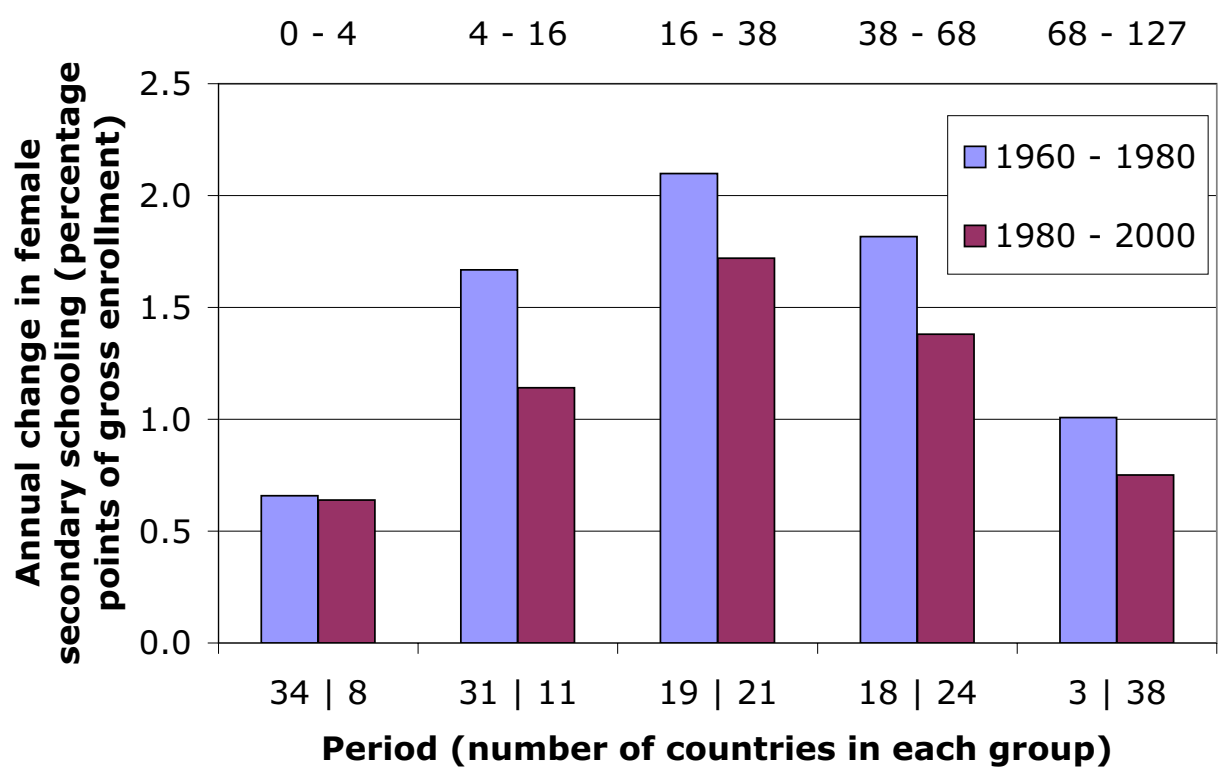

Source: World Bank, World Development Indicators 2005 


\section{Figure 16: Tertiary School Enrollment,} total

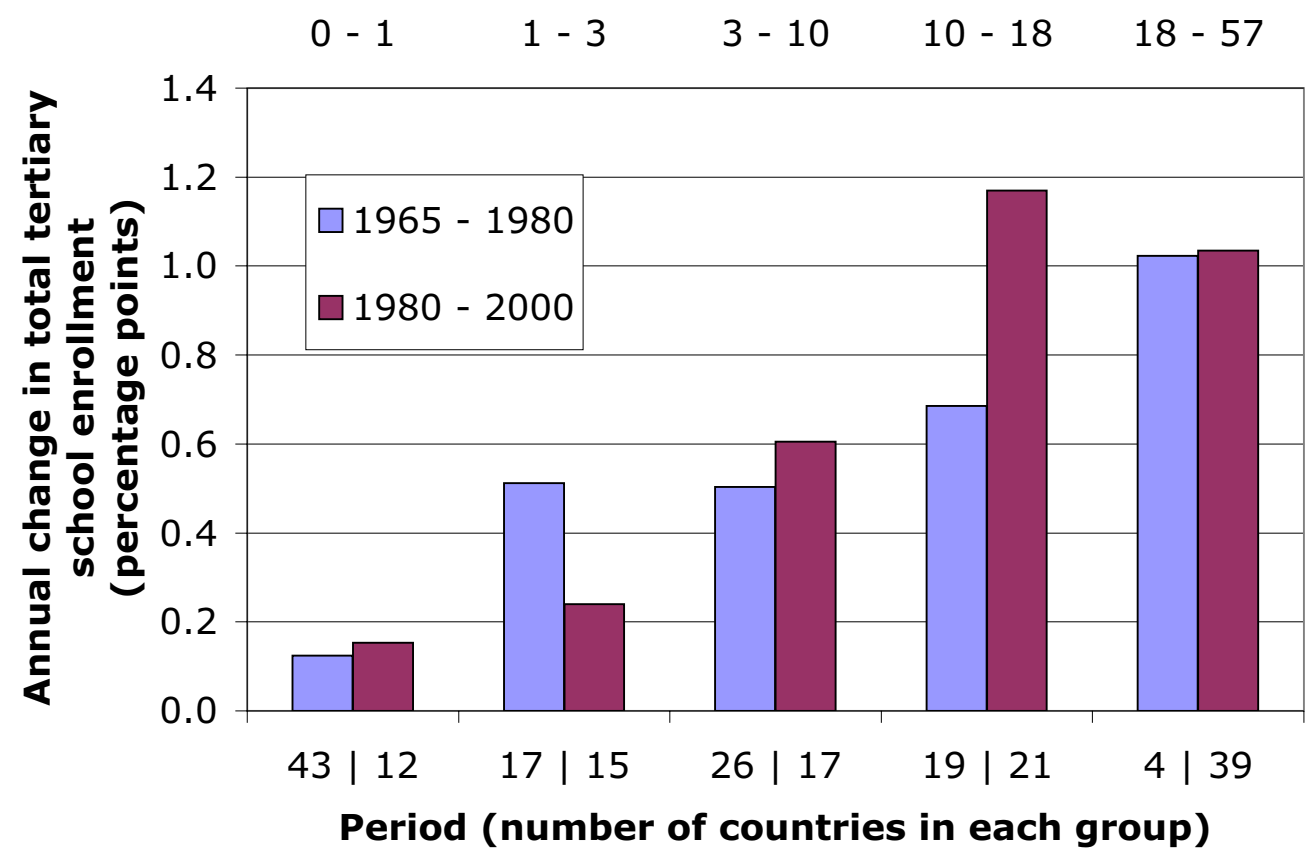

Source: World Bank, World Development Indicators 2005

Figure 17: Literacy Rates, adult total

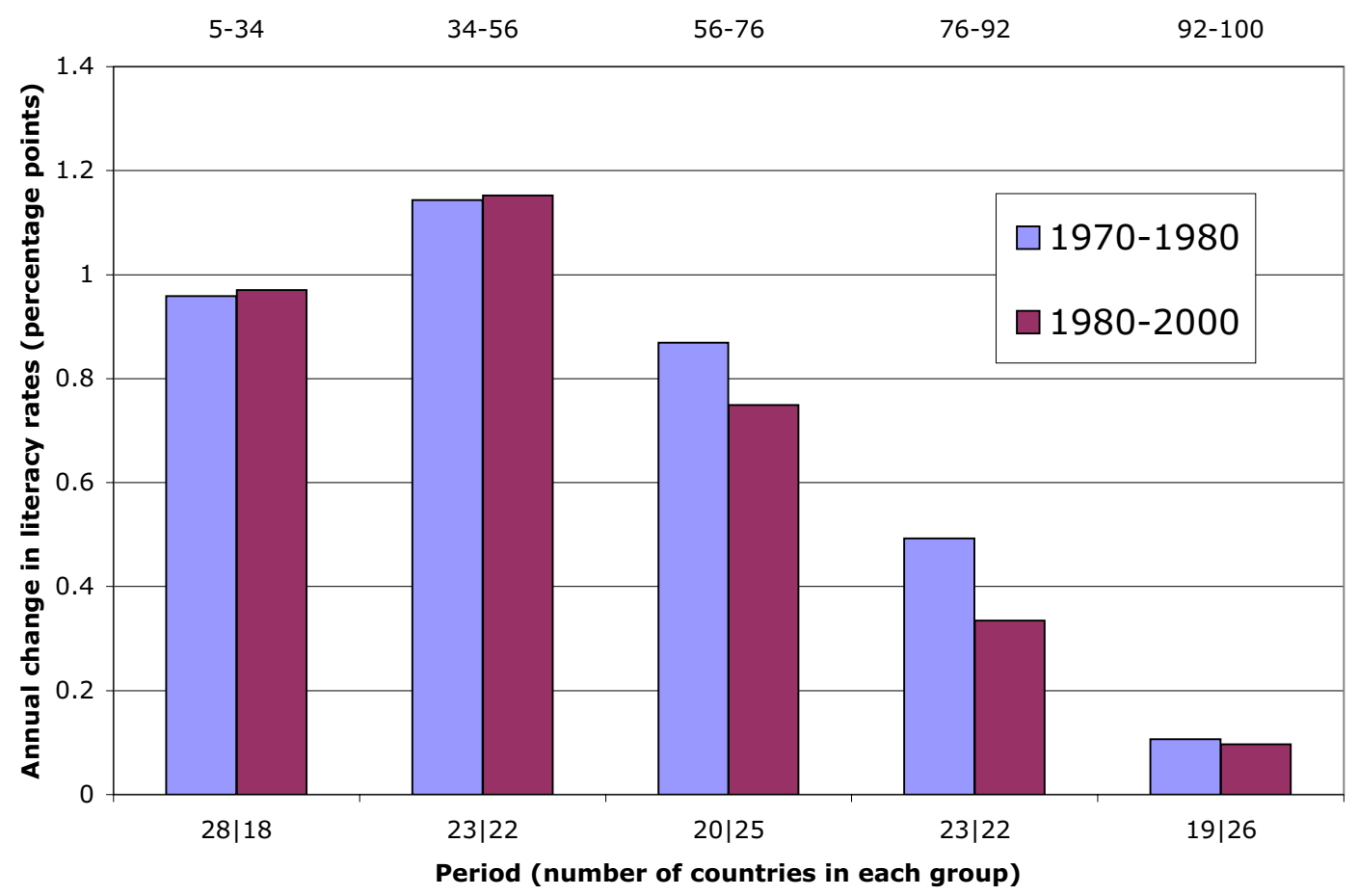




\section{Exceptions: China and India}

There are a few countries that have actually grown much faster since 1980 than in prior decades. Among them are China and India, the world's two most populous countries - China now has 1.3 billion people and India about a billion. Since these countries have adopted some of "globalizing" or "liberalizing" reforms over the last 25 years, it is sometimes argued on the basis of these countries' experiences that the overall set of reforms implemented by low- and middle-income countries worldwide have been a success.

There are two arguments here. First, since these two countries contain close to half of the entire population of the developing world, if we look at people rather than countries, the policy changes of the last quarter century have succeeded. The problem with this argument is that if we are looking at policy changes, we need to look at countries. Individuals do not control the investment, trade, interest rate, budget, and other economic policies that affect their ability to make a living. It is their governments that make these choices. But if a set of policy reforms is implemented over a long period of time in 80 or 90 countries, and only a few show higher growth rates - and the vast majority show slower, and often drastically slower growth this provides at least a prima facie case that the reforms have failed. This is true even if those few success stories happen to be countries with a lot of people.

The other argument is that a few success stories demonstrate that the reforms can work, if only they are correctly implemented. It is possible that all the other countries didn't implement them fully enough, or in the right way. O ne of the World Bank's answers to skeptics has been to group countries into "globalizers" and "non-globalizers" and show that the globalizers have grown faster over the last decade or so. The "globalizers" were the countries that showed the most rapid increase in trade as a percentage of their economies. ${ }^{14}$
But even if it were true that some set of "globalizing" countries - i.e. the ones that correctly implemented a set of liberalizing reforms - could be found to do better than the rest during the last 25 years, it would still not explain the long-term drop in the average rate of growth for the period. In Latin America, for example, Chile is the only country that has grown at a faster rate over the last 25 years than it did previously. ${ }^{15}$ Whatever Chile did that was successful, it would not explain why the last 25 years have been such a disaster for Latin America. It is simply not plausible to argue that Chile is the only country in the region that carried through the recommended reforms far enough to achieve benefits. If the nature of the reforms are such that anything less than full implementation leads to sacrifice without gain, and the political obstacles are so great that few countries can attain this level of reform, then most countries would probably be making the right decision by not attempting to follow the reform path. A handful of success stories cannot explain the sharp slowdown in economic growth in the vast majority of low and middle-income countries.

China has been most often cited as a globalization or liberalization success story, including trade and investment liberalization. And indeed since 1980 it has had one of the fastest growing economies in world history: GD P per person grew by an incredible average of 7.15 percent, increasing sixfold in 25 years to become the second largest economy in the world. But it did so under a set of economic policies strikingly different than the reforms implemented in the vast majority of low- and middle- income countries.

First, China did not liberalize its trade in most goods until it could compete in those areas in world markets. As late as 1992 its average tariff was still over 40 percent, about four times the level that Latin America had in 1974, before liberalization there. To the extent that trade liberalization

\footnotetext{
${ }^{14}$ See e.g. D ollar and Kraay, "Trade G rowth, and Poverty," The World Bank. June 2001.

${ }^{15}$ This is mostly since 1990; the Chilean economy grew by more than 60 percent per capita in the 1990s.
} 
contributed to China's growth, it may be because it was done carefully so as not to disrupt existing production - unlike the indiscriminate opening up to imports that was adopted in many other countries.

In fact China's transition to a mixed economy - with increasing use of markets - was carried out gradually and carefully. There were pilot projects, Special Economic Zones (in the 1980s) to experiment with foreign capital and technology, and gradual liberalization of prices. All this was deliberately designed so as to be able to correct mistakes and expand upon successes, a logical thing to do when policy makers are entering uncharted territory. As late as 1996, state owned and collective enterprises accounted for 75 percent of urban employment; even today, 25 years into China's economic transition, they still account for more than one-third of urban jobs. ${ }^{16}$ This stands in sharp contrast to the "shock therapy," massive and rapid privatization, and rapid decontrol of prices that led to an economic collapse and loss of nearly half of Russia's GDP in five years. That China has been able to manage its transition without any such setbacks - and by contrast with record-breaking economic growth over a 25-year period - is a compelling example of how important economic policy decisions can be.

Even today, China's banking system is dominated by four state-owned banks, which have more than 60 percent of the nation's deposits, assets, and credit. Foreign influence in the financial system is minimal. And even after the recent revaluation of the Chinese renminbi, which included some changes to allow more flexibility in its peg to the dollar, foreign currency flows remain strictly controlled.

Foreign direct investment (FDI) in China has soared from $\$ 19$ billion in 1990 to more than $\$ 53$ billion

\footnotetext{
${ }^{16}$ See Prasad, Eswar, ed. "China's G rowth and Integration into the World Economy," International Monetary Fund. Washington, DC. 2004
}

annually today ${ }^{17}$, and it has certainly contributed to China's growth. But even here the government has had a very big role in shaping and directing this investment, and approving investments that would fit in with the country's development goals. These include such priorities as producing for export markets, a high level of technology (with the goal of transferring technology from foreign enterprises to the domestic economy), hiring local residents for managerial and technical jobs, and not competing with certain domestic industries. China's policy toward foreign investment has therefore been directly opposed to the major worldwide reforms of recent decades, including the rules of the WTO; the same is also true in the important area of intellectual property.

In short, China's economic success over the last quartercentury cannot simply be summed up - as it so often is - as an example of the success of the overall package of reforms that most developing countries have adopted over the last 25 years. The same is true for India, which is a less spectacular but still important exception to the general slowdown of growth after 1980. The Indian economy has grown by an average of 3.8 percent annually, per capita, from 1980-2005 - more than double the 1.6 percent annual rate from 1960-80. But it is difficult to attribute this transformation to "globalizing" reforms. As in China, the big increase in economic growth in India took place more than a decade before liberalization began. India's growth took off in 1980, more than a decade before the liberalizing reforms of 1991. Tariff revenue, measured as a share of imports or GDP, actually increased significantly during the 1980s, as did other measures of trade protection. Similarly, trade increased several times faster in India in the 1990s than it did in the 1980s. Beginning in 1991, the government embarked upon a rapid reduction of trade barriers, privatization, some deregulation of financial markets, measures to encourage foreign direct investment, and other reforms. But growth did not increase

\footnotetext{
${ }^{17}$ World D evelopment Indicators, 2005 (2003 data for FDI).
} 
over its 1980s rate. So while there is plenty of room for debate over what caused India to increase its growth rate at a time when most developing countries were moving in the opposite direction, the 1990s reforms do not look like the main answer. ${ }^{18}$ India's success story also included such non-orthodox policies as strict currency controls. Even after the liberalization of the 1990s, India retained a higher level of protection for its domestic markets than most other developing countries.

${ }^{18}$ See D ani Rodrik and Arvand Subramaniand, "From 'Hindu G rowth to Productivity Surge: The Mystery of the Indian G rowth Transition." March 2004. 


\section{Conclusion: What Went Wrong?}

The past quarter century has seen a sharp decline in the rate of growth for the vast majority of low- and middleincome countries. Accompanying this decline has been reduced progress for the almost all of the social indicators that are available to measure health and educational outcomes. ${ }^{19}$ The methodology of this paper precludes the possibility that this reduced economic and social progress was a result of "diminishing returns," i.e., the increased difficulty of progressing at the same rate from a higher level. It is therefore likely that at least some of the policy changes that have been widely implemented over the last 25 years have contributed to this long-term growth and development failure. In some of the financial and economic crises that took place in the late 1990s for example in East Asia, Russia, and Argentina - it seems clear that policy mistakes contributed to severe economic losses. ${ }^{20}$

But it is generally difficult to show a clear relationship between any particular policy change and economic outcomes, especially across countries. There are many changes that take place at the same time, and causality is difficult to establish. It is certainly possible that the decline in economic and social progress that has taken place over the last 25 years would have been even worse in the absence of the policy changes that were adopted. But that remains to be demonstrated. In the meantime, a long-term failure of the type documented here should at the very least shift the burden of proof to those who maintain that the major policy changes of the last 25 years have raised living standards in the majority of

\footnotetext{
${ }^{19}$ It is worth noting the limited basis of the comparisons used in this analysis. In particular, it would have been desirable to measure national performances on a variety of environmental measures. Unfortunately, there are no widely available sets of data for most countries on these measures; if such data could be assembled, this would be an important part of a more complete evaluation of the progress of the last quartercentury.

${ }^{20}$ See Steven Radelet and Jeffrey Sachs, "TheE astAsian Financial Crisis: Diagnosis, Remedies, Prospects." Harvard Institute for International Development. April 1998 and see Alan B. Cibils, Mark Weisbrot, and D ebayani Kar, "Argentina Since D efault: The IMF and the D epression." Center for Economic and Policy Research, September 2002.
}

developing countries, and encourage skepticism with regard to economists or institutions who believe they have found a formula for economic growth and development. Indeed, some economists have recently concluded that more "policy autonomy" - the ability of countries to make their own decisions about economic policy - is needed for developing countries. ${ }^{21}$ Most importantly, the outcome of the last 25 years should have economists and policy-makers thinking about what has gone wrong.

${ }^{21}$ This is the conclusion of Nancy Birdsall, D ani Rodrik, and Arvind Subramanian. ("How to Help Poor Countries," Foreign Affairs, New York:Jul/ Aug 2005. Vol. 84, Iss. 4, p. 136-152) With regard to China, the authors ask rhetorically, "Would China have been better off implementing a garden-variety World Bank structural adjustment program in 1978 instead of its own brand of heterodox gradualism?" 